\title{
Towards a Prescriptive Theory of Dynamic Capabilities: Connecting Strategic Choice, Learning, and Competition
}

\section{Citation}

Pisano, Gary P. "Towards a Prescriptive Theory of Dynamic Capabilities: Connecting Strategic Choice, Learning, and Competition." Harvard Business School Working Paper, No. 16-146, June 2016.

\section{Permanent link}

http://nrs.harvard.edu/urn-3:HUL.InstRepos:27882661

\section{Terms of Use}

This article was downloaded from Harvard University's DASH repository, and is made available under the terms and conditions applicable to Open Access Policy Articles, as set forth at http:// nrs.harvard.edu/urn-3:HUL.InstRepos:dash.current.terms-of-use\#OAP

\section{Share Your Story}

The Harvard community has made this article openly available. Please share how this access benefits you. Submit a story. 
Towards a Prescriptive Theory of Dynamic Capabilities:

Connecting Strategic Choice,

Learning, and Competition

Gary Pisano

Working Paper 16-146 


\title{
Towards a Prescriptive Theory of Dynamic Capabilities: Connecting Strategic Choice, Learning, and Competition
}

\author{
Gary Pisano
}

Harvard Business School

Working Paper 16-146 


\section{Towards A Prescriptive Theory of Dynamic Capabilities:}

\section{Connecting Strategic Choice, Learning, and Competition}

\section{Working Paper}

Draft 3.5

June 25, 2016

Gary P. Pisano

Harry E. Figgie Professor of Business Administration Harvard Business School

This paper is an extension revision of manuscript originally entitled "A Normative Theory of Dynamic Capabilities: Connecting Strategy, Know-How, and Competition" (HBS Working Paper \#16-036)

\footnotetext{
* I would like to thank Pamela Adams, Felix Arndt, Giada di Stefano, Giovanni Dosi, Pankaj Ghemawat, Shane Greenstein, Michael Jacobides, Franco Malerba, Lamar Pierce, Michael Tushman, and Eric Van der Steen for many helpful comments on earlier drafts of this paper. All errors and shortcomings are the sole responsibility of the author. The financial support of the Harvard Business School Division of Faculty Research and Development is gratefully acknowledged.
} 


\begin{abstract}
The field of strategy has mounted an enormous effort to understand, define, predict, and measure how organizational capabilities shape competitive advantage. While the notion that capabilities influence strategy dates back to the work of Andrews (1971), attempts to formalize a "capabilities based" approach to strategy only began to take shape in the past twenty years. In particular, the publication of Teece and Pisano (1994), Teece, Pisano, and Shuen (1997), and Eisenhart and Martin (2000) works on "dynamic capabilities" triggered a flood of debate and discussion on the topic. Unfortunately, the literature on dynamic capabilities has become mired in endless debates about definitions and has engaged in an elusive search for properties that make organizations adaptable. This paper argues that the research program on dynamic capabilities needs to be reset around the fundamental strategic problem facing firms: how to identify and select capabilities that lead to competitive advantage. To this end, the paper develops a framework that attempts to connect firms' capability search strategies with their strategies in product markets. It frames firms' capability search strategies as choices among different types of capability enhancing investments. The key distinguishing feature of capabilities in this framework is their degree of fungibility: capabilities span a continuum ranging from highly general-purpose (e.g. quality management) to highly market-specific (e.g. knowing how to manufacture an airplane wing). To illustrate the potential of the framework to shed new light on traditional strategy questions, the paper applies the framework to explore some unexplained features of Penrosian diversification strategies. The paper concludes by suggesting a research agenda for dynamic capabilities.
\end{abstract}




\title{
Towards a Prescriptive Theory of Dynamic Capabilities: \\ Connecting Strategic Choice, Learning, and Competition
}

\author{
Gary P. Pisano \\ Harry E. Figgie Professor of Business Administration \\ Harvard Business School \\ Draft 3.5
}

June 25, 2016

\section{Introduction}

The field of strategy has mounted an enormous effort to understand, define, predict, and measure how organizational capabilities shape competitive advantage. While the notion that capabilities influence strategy dates back to the work of Andrews $(1971)^{1}$, attempts to formalize a "capabilities-based" approach to strategy only began to take shape in the past twenty years. In particular, the publication of Teece and Pisano (1994), Teece, Pisano, and Shuen (1997), and Eisenhardt and Martin (2000) works on "dynamic capabilities" triggered a flood of debate and discussion on the topic. ${ }^{2}$ Despite such a concerted intellectual effort, progress toward a strategic theory of capabilities or even a coherent framework has been disappointing. For instance, in a comprehensive review of the literature on the topic, Peteraf et al. (2013) put in starkly: "From the intensity of this research effort and evident interest in the topic, one might surmise that there exists a common understanding of dynamic capabilities. This is far from the case. The construct remains open to a variety of conceptualizations and interpretations concerning even its most basic aspects, including how dynamic capabilities are defined." The attempt to parse the dynamic capabilities concept at ever-finer levels of detail has led to multiple competing definitions (for a comparison, see Dosi et al. 2008). Even the most ardent supporters of a dynamic capabilities approach to strategy would have to admit that the framework has made little progress theoretically, and has gained even less traction among practitioners.

\footnotetext{
${ }_{1}^{1}$ Other early antecedents include Hayes (1985), Winter (1987), and Prahalad and Hamel (1990)

${ }^{2}$ According to a recent review by Peteraf et al. (2013), since 2006 alone, articles on "dynamic capabilities" have appeared in management journals at a rate of more than 100 per year.
} 
Perhaps this lack of convergence should not be surprising. Both capabilities and strategy are broad realms, lending themselves to a range of perspectives. Debate may simply reflect a healthy process of generating and selecting among multiple competing ideas, especially early in the intellectual life cycle of a concept (Helfat and Peteraf 2009). This paper suggests a deeper underlying cause. The literature has become obsessed with the wrong problem. Strategic theories must always concern choice, and competitive strategy theories (including capabilitybased ones) must concern how choices affect competitive outcomes. This is not the direction taken by the dynamic capabilities literature, however. The existing literature has engaged in an illusive search for the properties of firms (so-called 'dynamic capabilities') that make them adaptable. By focusing on the problem of adaptability, the dynamic capabilities literature has missed an opportunity to explore a more fundamental (and managerially relevant) strategic question: how do firms' choices about capability investments shape competitive outcomes? This paper develops a framework to explore this question. It is based on the original premise of dynamic capabilities (Teece and Pisano 1994; Teece, Pisano, and Shuen 1997) that capability identification, selection, and creation is an important strategic decision—just as important to competitive performance as decisions about which markets to enter, how to position, in which markets to exploit existing resource position, how to deter entry, and other "traditional" strategic variables. Just as firms compete in product markets, they also compete to create technological, operational, and organizational capabilities that provide them advantage in those product markets. Decisions about product market entry and position and decisions about capability creation are intimately linked. The job of a capabilities-based theory of strategy should be to provide conceptual and practical insights about these links. More specifically, a capabilitybased theory of strategy should identify the choices available to firms and the consequences of those choices under different competitive circumstances.

The framework presented here views the firm's capability problem as one of searching for and choosing among different types of capability enhancing investments. Throughout the paper, we follow Winter's (2003) definition of a capability as a collection of routines that enable an organization to perform some activity on a consistent (repeatable) basis. At any point in time, a 
firm possesses a repertoire of capabilities that span a continuum from highly general-purpose (e.g. mechanical engineering, organic chemistry, assembly manufacturing, quality improvement, financial management, etc.) to highly market-specific (compact car design, immunotherapeutic cancer drug discovery, retail banking in a particular region, high-volume semiconductor manufacturing, etc.). The firm's capability strategy involves choices between deepening their existing capabilities versus broadening their repertoire to include new sets of capabilities.

Obviously, firms can do both, but resource constraints mean that they must make choices at the margin. In addition, a firm's capability choices are partially constrained—they are neither complete prisoners of their past nor can they change instantly and infinitely.

The paper conjectures that optimal capability strategies are partially determined by the degree to which general-purpose and market-specific capabilities are either complements or substitutes. This principle suggests that the strategic value of general-purpose capabilities may be much higher than commonly viewed in the strategy literature. To illustrate the applicability of this principle, we examine the case of Penrosian diversification strategies. This analysis suggests that strong complementarities between a firm's existing general purpose capabilities and novel capabilities required to diversify into new markets can partially explain previously unexplored aspects of Penrosian diversification. The paper concludes by offering more general suggestions about avenues for future research.

\section{Focal Questions For a Capabilities-Based Theory of Strategy}

Theory development is one of identifying and filling gaps between causal explanations and observed phenomenon (Kuhn 1962). The strategy field has been undergoing this "gap filling" process for several decades. It began with the puzzle (identified by industrial organization economists as far back as the 1930s) that some industries were, on average, more profitable than others. This gap was filled by set of theoretical and empirical research comprising the "structure-conduct-performance" paradigm, that ultimately lead to the creation of Porter's (1980) "five forces" framework of competitive strategy. As a framework, "five forces" has been remarkably successful. It is logically consistent. It can explain a set of facts well (for instance, 
why, on average, airlines are much less profitable than pharmaceutical companies). It has held up to empirical testing. It is flexible enough to handle a broad range of strategic contexts and problems. And it could be distilled into useful analytical tools and concepts to help practitioners make sense of the world and develop strategies. While subsequent work in economics, particularly game theory, expanded these notions and incorporated more sophisticated firm-tofirm interactions, and probed more deeply into specific strategic contexts (e.g. capacity strategies, entry deterrence), the basic edifice has been quite robust.

But there was a puzzle that Porter's and subsequent economic approaches could not explain: namely, the relatively high degree of intra-industry variability in profitability over long periods (Lippman and Rumelt 1982, Rumelt 1984, Rumelt 1991). Many companies within the same industry following similar strategies had very different performance. This "gap" between theory and observation was filled by the development of resource-based theories (Teece 1982, Wernerfelt 1984, Barney 1991, Amit and Schoemaker 1993). The resource-based theory of strategy sought to explain intra-industry performance differences with firm-specific (non-imitable) "resources": tangible and intangible assets like skills, capabilities, reputation, brand equity, etc. Given the theory's intellectual connection to Penrose, it is not surprising that resource-based theory made its most precise predictions on the matter of corporate diversification (e.g. Teece 1982, Montgomery and Wernerfelt 1988).

During the 1980s and early 1990s, a series of studies largely undertaken by scholars outside the strategy field were creating another puzzle. Statistical and case studies of product development and operational performance (Abernathy et al. 1983; Garvin 1988: Hayes and Clark 1986: Clark and Fujimoto 1990: Pisano 1996: Iansiti 1998) suggested that some organizations do a better job creating and developing those capabilities that lead to sustained competitive advantage. Moreover, this line of work indicated that some firms were more capable of renewing their skills and building new competences. Resources (broadly defined) were not static.

Like Porter's five forces framework, resource-based theories had little to say about the dynamics of capability-creation. It could not explain why, for instance, Toyota had accumulated stronger capabilities in product development and manufacturing than General Motors. It could not 
predict whether a firm like Intel would maintain its lead in technology over a rival like AMD, even though such a capability advantage may be critical to Intel's competitive advantage in the microprocessor market. And resource-based theory provided little guidance to firms about the kind of capabilities they might attempt to develop in order to secure or sustain a competitive advantage (beyond general properties like inimitability and uniqueness). Such dynamics of capability accumulation were completely outside the realm of both Porter and resource-based frameworks.

\section{The Dynamic Capabilities Framework}

Responding to this gap, Teece and Pisano (1994) and Teece, Pisano, and Shuen (1997) outlined a framework-generally referred to as "dynamic capabilities"--for understanding firm level capability differences. The "dynamic capabilities" framework conjectured that firm level differences in capabilities were rooted in three factors:

1. Asset Positions: Following evolutionary economic and path-dependence logic, a firm's ability to change their future repertoire of capabilities is constrained by its current stock of capabilities. Teece and Pisano (1994) used the term "assets" broadly to define the legacy resources (knowledge, technical skills, organizational competences, etc.) that shaped the firm's options for future capability expansion.

2. Processes: Firms can "reconfigure" their asset positions by investments and other managerial interventions. But a firm's capacity to reconfigure is not unlimited. It depends on a set of 'higher-order' routines (like governance structures, resource allocation processes, management systems, etc.) that shape organizational adaptability. It is this capacity to reconfigure a firm's asset positions and specifically the "processes" that underlie this capacity that Teece and Pisano (1994) called "dynamic capabilities."

3. Paths: Because most capabilities are cumulative and develop over time through a series of coordinated investments, they involve commitments to "paths", rather than discrete projects. A key strategic problem for firms is to identify and commit to paths for capability creation that lead to competitive advantage. Managerial discretion in the selection of 
paths-along with constraints imposed by pre-existing asset positions and processes for reconfiguration--can lead to differences in firm capabilities.

The relationship between these factors, and how they influence competitive outcomes is depicted in Figure 1 below.

Figure 1: The Dynamic Capabilities Framework

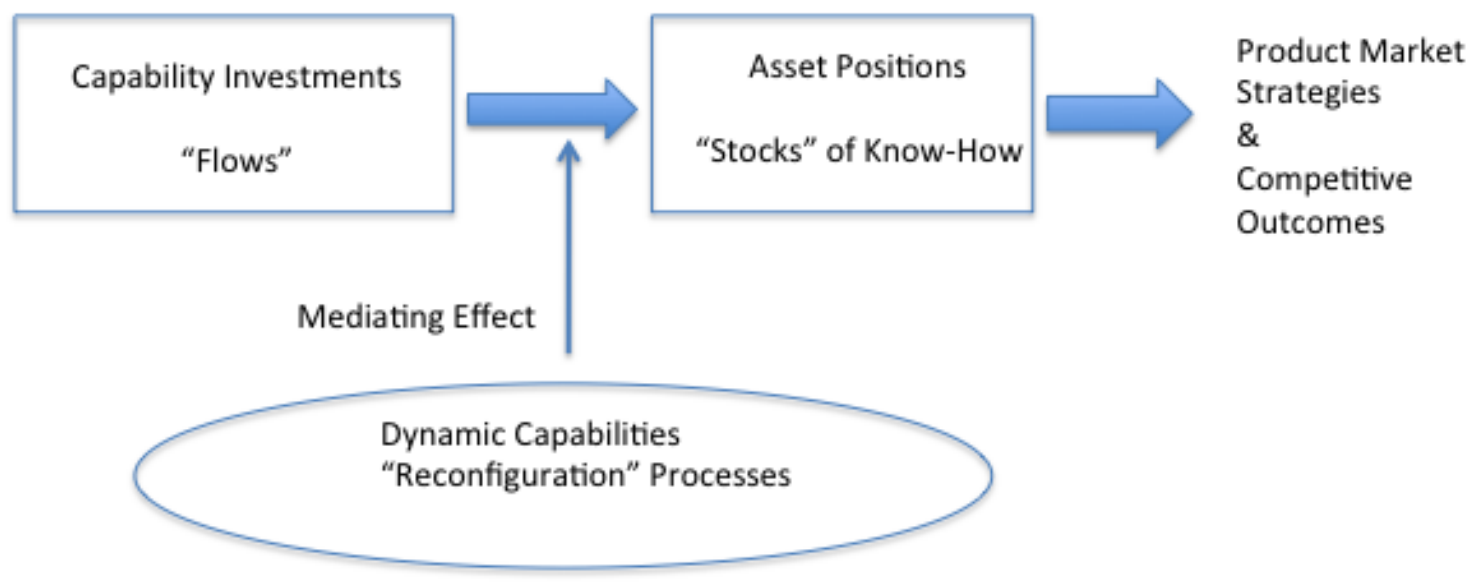

The dynamic capabilities framework had both descriptive and normative implications. It could be use to help explain firm-level differences. But it also aspired to inform managers about how to make better capability decisions. The dynamic capabilities framework argued that these kinds of choices were important to a firm's competitive advantage, and thus should be a focal point for strategic analysis. The third leg of the framework—choices about paths—was the most explicitly managerial, but the original formulations in Teece and Pisano (1994) and Teece, Pisano, and Shuen (1997) offered only high-level prescriptive guidance. It was hoped at the time that future research would illuminate many more details and principles about how managers should make capability investment commitments.

Unfortunately, this is not the issue that became the focal point of "dynamic capabilities" literature. ${ }^{3}$ That literature has come to focus on the question of why some firms are more adaptable than others. Specifically, the literature has been consumed with the second leg of the

\footnotetext{
${ }^{3}$ For excellent reviews, see Dosi et al(?) (2008), Helfat and Peteraf (2009), and Peteraf et al. (2013)
} 
framework---identifying and specifying exactly what "dynamic capabilities" are and how they contribute to a firm's capacity to adapt to change and reconfigure their competences and assets. This is important work and has led to interesting insights about organizational change. But such a capacity for change alone tells us nothing about competitive outcomes, other than the obvious fact that a more flexible firm will likely do better in a more uncertain environment. As Winter (2003, page 994) points out: "Some of the mystery and confusion surrounding the concept of dynamic capabilities arises from linking the concept too tightly to notions of generalized effectiveness at dealing with change and generic formulas for sustainable competitive advantage."

Telling managers they should create organizations that are adaptable is fine and developing good theories about what makes a firm adaptable is certainly a worthwhile endeavor. However, understanding the merits and drivers of organizational adaptability does not constitute the basis of a helpful theory of strategy. Investments in certain types of capability represent commitments that might actually make the firm less adaptable, and yet more competitive in a specific context. There is a trade-off. "How do I make my enterprise more adaptable?" is a very different question than "What capabilities should I attempt to create to gain a competitive advantage and what trade-offs does this involve?" The former is not a strategy question, the latter is.

\section{Explaining Capability Differences Across Firms: Does Management Matter?}

Differences in capability alone are not enough to motivate the need for a capabilitiesbased theory of strategy. For capabilities to be a "strategic variable", managers must be able to influence their creation and evolution. ${ }^{4}$ Two null hypotheses must first be evaluated. First, are differences in capabilities rooted in random factors as suggested by Barney (1986)? If so, then they are beyond management control (and thus, outside the realm of strategy). Second, are these differences in capabilities purely a function of firm history, as suggested by strong forms of path dependence theories (see e.g. ecological theories such as Hannan and Freeman 1977)?

\footnotetext{
${ }^{4}$ On this question, see also Andriani and Cattani (2016)
} 
Following this logic, some researchers have even gone as far as to call the strategic manager's job "futile in the face of environmental disruptions" (Dew, Goldfarb, and Sarasvathy 2006). If capability creation is either a purely random or completely determined process, then the third leg of the original "dynamic capabilities" framework is normatively irrelevant. Existing theories (such as resource-based theories) already help us understand how extant capabilities may be deployed for competitive advantage.

While provocative, these two hypotheses are not supported by available evidence from empirical studies and detailed cases studies. Historians like Chandler documented dramatic differences across firms in terms of administrative, operational, and distribution capabilities and the potent role that the visible hand of management played in shaping these capabilities (Chandler 1990). Detailed empirical analyses of productivity indicate that significant productivity differences across firms can be explained by differences in management practices, policies, and decisions (see e.g. Hayes and Clark 1986, Bloom and van Reenen 2007) Based on their analysis of data collected from 5850 firms across seventeen countries, Bloom and Van Reenen (2010) concluded: "The patterns within our large sample of management data across firms and countries have led us to believe that one important explanation for the large differences in productivity between firms and countries—differences that cannot be readily explained by other factors—is variations in management practices. ${ }^{5}$ Similar results can be found in the research exploring interfirm differences in quality (e.g. Garvin 1988, Womack et al. 1991), manufacturing flexibility (Upton 1995), and product development performance (Clark and Fujimoto 1990, Pisano 1996, lansiti 1998, Henderson and Cockburn 1994). While a number of studies highlight the challenges industry incumbents face adapting their capabilities to dramatic technological changes (e.g. Dosi 1984, Malerba 1985, Tushman and Anderson 1986, Henderson and Clark 1990, Christensen 1997), failure to adapt is not inevitable. Numerous empirical studies indicate that firms differ in their capacity to adapt their capabilities to major environmental upheavals, and that at least some of these differences are rooted in management behaviors and practices (see e.g. Henderson and Clark 1990, Tripsas 1997, and O’Reilly and Tushman 2008).

\footnotetext{
${ }^{5}$ Bloom and Van Reenen (2010) page 222.
} 
The mass of available empirical evidence on the drivers of the critical operating capabilities behind productivity, quality, manufacturing flexibility, and $R \& D$ performance clearly indicates that "management matters." The hypotheses that firm capabilities are somehow randomly distributed among firms or determined invariably by their past are not supported by the available empirical evidence.

\section{Strategically Relevant Capabilities}

While the body of evidence, when taken in its entirety, suggests that managerial discretion can shape an organization's capabilities, such discretion is by no means unlimited. Creating new capabilities is costly, time consuming, hard to fully predict and ultimately bounded. An organization like IBM may, over decades, evolve from a maker of mechanical office equipment to a computer company to an IT services and consulting company, but it is unlikely that IBM could have gone from being a computer company to an aerospace company or drug company

overnight. Strategically relevant capability creation occupies a "middle zone" between the two extremes of, on the one hand, complete, unbounded adaptability (as seen through the lens of traditional economic theory) and, on the other hand, complete, history-determined inertia (as seen through the lens of a strong path-dependence theory). For any given firm at any point in time, certain capabilities are essentially economically infeasible because they would be too costly to develop (e.g. Honda becoming a capable drug discoverer within a year); and there are capabilities which are so close to the firm's existing repertoire, they are can be added at trivial marginal cost (e.g. Honda developing the capability to manufacture a next generation Honda Accord). Strategically relevant capabilities are intermediate between these extremes. They are costly, time consuming, and uncertain to develop, but not so much so that they represent a strategically infeasible option (see Figure 2).

Figure 2: Capabilities and Strategic Relevance 


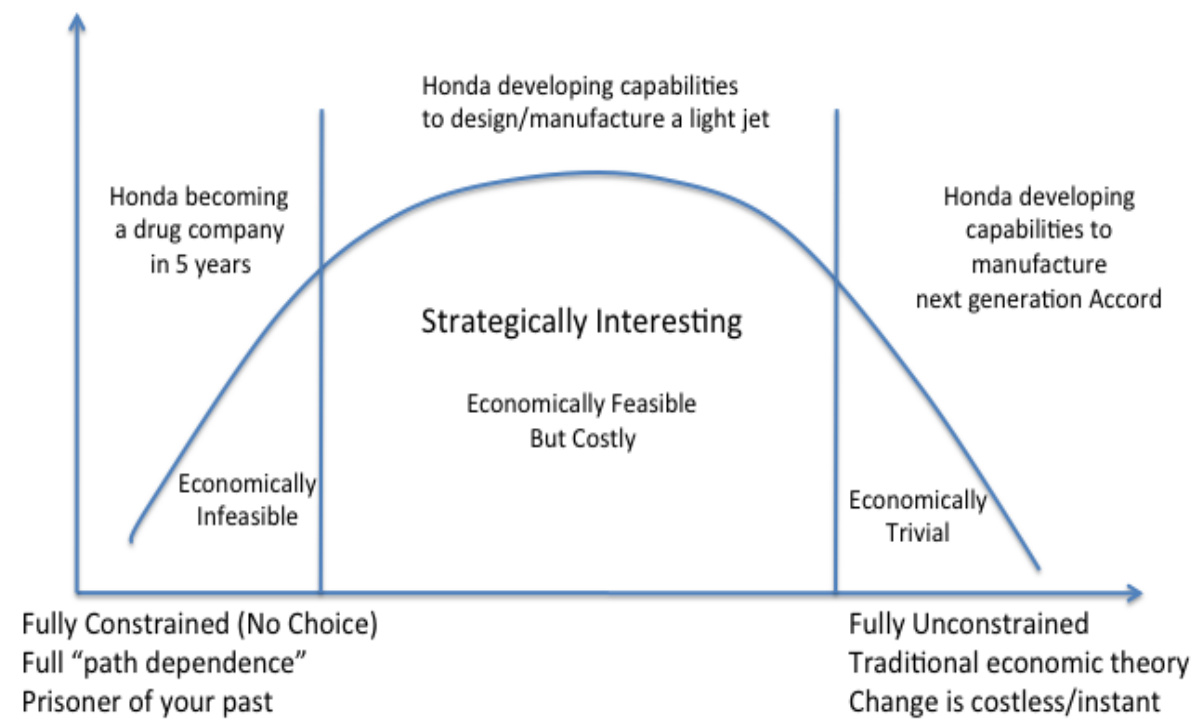

\section{Capability Creation: Uncertainty, Search, and Learning}

Competition occurs at two levels. One is the visible level of product market competition. This level concerns familiar decisions like entry strategies, positioning and deterrence. This level is relatively "visible" because most strategic product market moves of firms are somewhat observable using public data sources (annual reports, press releases, market price data, etc.). It concerns such familiar strategy questions as "What kind of next generation aircraft should Boeing develop to gain an advantage over Airbus?"; "How should Apple position the Apple Watch relative to Samsung's watch-like device?"; "Should Honda enter the market for light private jets?". The other level of competition-much less visible to outsiders-concerns the competition to create operational, organizational, and technological capabilities. Here, we get into the "guts" of how organizations do things. This level of competition concerns such questions as: "How much should Boeing be investing in novel materials?", "How much should Apple invest in developing novel battery technologies?"; "Should Honda be investing heavily in machine learning?" A capabilities-based theory of strategy should link product level competition and capability-level competition. It should also be congruent with the realities and complexities of the capability creation process itself.

Capability formation results from various kinds of investments, including formal R\&D 
projects, technology adoption, enhancements to physical and human capital, formal and informal experimentation, operating process redesign, and autonomous learning by doing. Building capabilities, though, involves more than simply "choosing" where to invest. An organization may have a desired set of capabilities in mind when they invest, but the outcome of such investments can be highly uncertain. The target capability may not always be clear, and even when it is, the organization may not have a good understanding of the path to get there. They may wind up with different capabilities than they had originally planned (Fujimoto 1999). Posed simply, organizational capabilities have an evolutionary character-they emerge from uncertain processes of search and experimentation-- rather than a deterministic one (see e.g. Nelson and Winter 1982).

There are two sources of uncertainty in the search for capabilities. The first is uncertainty associated with the difficulty of predicting the outcome of any capability-building process. There can be gaps between the intended and actual capability created by an investment. Honda might decide it wants to develop engineering capabilities needed to design autonomous vehicles, but achieving such skills is by no means straightforward. It may fail completely in building the target competences or it may wind up with a different set of competences than it originally planned. ${ }^{6}$ This type of supply side uncertainty in capability creation stems from uncertainty regarding the boundaries of a firm's capabilities. Ex ante, it may be hard for a firm's managers to predict exactly what the firm can learn or how far it can "stretch" beyond its existing capabilities.

The second source of uncertainty in the search for capabilities stems from uncertainty regarding the economic value of a capability (once created) in particular markets. Such demand side uncertainty stems from lack of information about future customer needs and rivals actions. Ex ante, it may be hard to predict whether a targeted capability will ultimately be a valuable resource to the firm. Assuming Honda succeeds in creating the capabilities to create a light jet, the value of such capabilities ultimately hinges on uncertain future conditions in the light jet market (demand, customer willingness to pay, relative positioning of rivals, etc.). In general, uncertainty regarding the value of capabilities likely correlates with the maturity of the market in

\footnotetext{
6 Fujimoto's (1999) historical analysis of the Toyota Production System provides vivid evidence of the divergence between actual and intended capabilities at Toyota.
} 
which they are to be deployed. In more mature markets (like automobiles), because customer preferences and patterns of rivalry are more firmly established, there is less uncertainty regarding which capabilities should be competitively valuable. In less mature market (e.g. self driving automobiles), customer preferences have not formed and evolve with experience (Clark 1985). This creates greater uncertainty with respect to the value of specific capabilities.

Due to both supply side and demand side uncertainty, it is impossible for a firm to fully predict the capabilities it will accumulate and the ultimate value of those capabilities. As a result, a firm's capability strategy should be thought of as defining a pattern of search for types of capabilities, rather than as a choices about specific capabilities. Each type of uncertainty has implications for how we should think about the dimensions of this search. Demand side uncertainty is contingent on whether the firm is attempting to develop highly market-specific capabilities versus general-purpose capabilities. Supply side uncertainty is contingent on whether the firm is deepening its existing capabilities versus broadening its repertoire of capabilities into new domains.

\section{General-Purpose vs. Market-Specific Capabilities}

Some capabilities are more fungible than others, and thus involve lower degrees of commitment to specific markets or product market strategies (Ghemawat and Pisano 1997). At one extreme, we can define general-purpose capabilities as capabilities which can be deployed in a relatively broad range of uses and markets. Consider, for example, Honda's capabilities in mechanical engineering, Toyota's in quality management, or Google's in machine learning. These types of capabilities are not only useful in the firms' core markets, but also have broad applicability to other sectors. At the other extreme, there are capabilities that can only be utilized in a very narrow range of uses. Designing a car chassis, for instance, requires solving a host of specific engineering problems associated with the unique requirements and uses of a car (e.g. the chassis is stressed at different points depending on the weight of the vehicle, the conditions of the road, the speed of the vehicle, the RPM of the engine, whether the vehicle is turning, breaking, or accelerating, etc.). And knowledge about how to design a chassis for a BMW 3- 
series is not exactly the same as what is required to design a chassis for a full-sized Ford pick-up truck. These highly application-specific capabilities will be referred to here as market-specific. ${ }^{7}$

Market-specificity comes down to the degree to which knowledge is transferable across tasks or contexts (e.g. product categories, market segments, operating constraints, and geography). Differences in tasks and context may be quite subtle. For instance, Walmart's demonstrated capability to effectively operate large, low cost supermarkets throughout the US did not transfer well to many markets outside the US (e.g. Germany). While the differences between general-purpose and market-specific knowledge are a matter of degree, we will talk about them as discrete choices for convenience.

At first glance, it might seem that firms would only ever want to invest in highly marketspecific capabilities. After all, the literature on strategy has long argued that only specialized capabilities can underlie a competitive advantage. Porter (1996) for instance has argued that a general-purpose capability like "operational effectiveness" can never be a source of competitive advantage because it is easily imitated. But this thinking ignores two features of generalpurpose capabilities. First, general-purpose capabilities are not the same as "generic" capabilities. That is, general-purpose capabilities can also be firm-specific. A firm might have a unique, difficult-to-imitate capability that can also be leveraged across markets. Consider Toyota's capabilities in high quality manufacturing or Google's capabilities in machine learning. Both of these organizations enjoy fairly unique capabilities in these realms, and yet these capabilities have broad applicability across markets. Second, general-purpose capabilities provide a necessary foundation for market-specific capabilities. General-purpose and marketspecific capabilities can be complements. ${ }^{8}$ General-purpose capabilities are strategically important because they shape a firm's future potential market entry options. Toyota's capabilities in quality created an option for it to enter the luxury car segment. Google's general-purpose capabilities in machine learning have created options for it to make market -specific investments in driverless vehicles. Because general-purpose capabilities are (by definition) more transferable

\footnotetext{
${ }^{7}$ For earlier discussions of application specific know-how, see Winter (1987) and Breschi and Malerba (1997)

8 On the concept of complementarities as a source of advantage, see Milgrom and Roberts (1990) and Rivkin and Sigglekow (2003).
} 
across contexts and markets, they provide a hedge against market-specific demand uncertainty. Investments in general-purpose capabilities create options, while investments in market-specific capabilities are commitments to exercise those options. A firm's choices about investments in general-purpose versus market-specific capabilities have important consequences for both its current competitive position and its long-term market entry options. As such, these choices are fundamental to strategy.

\section{Deepening vs. Broadening Strategies}

A second dimension of a firm's capability strategy concerns the choice between deepening existing capabilities versus searching for novel capabilities outside the firm's current repertoire. Building capabilities to automate production of automobiles would be an example of a deepening strategy for a company like Honda. Building capabilities to be able to design and produce a light jet is an example of capability broadening for Honda. There are similarities between car design and aircraft design (e.g. both involve the application of mechanical engineering, aerodynamics, and electronic control systems), but airplanes and cars also involve some fundamentally different engineering problems. The distinction between broadening and deepening is also a matter of degree rather than kind. Some "new" capabilities are relatively more similar to the firm's existing capabilities than others.

Deepening strategies are akin to the concept of "local search" in the evolutionary economics literature (Nelson and Winter 1982) and to March's concept of "exploitation" (March 1991). All other things equal, deepening strategies entail lower supply side uncertainty than broadening strategies. Honda is more likely to be successful in deepening its manufacturing capabilities in car production than in broadening its capabilities to include light jet design.

A critical distinction between capability deepening and capability broadening strategies is the role played by learning from experience. Cumulative learning from experience is a critical mechanism through which firms deepen their existing capabilities. Firms often deepen their existing capabilities simply by using them. By definition, capability broadening involves some degree of separation from the company's experience base. As a result, broadening is less 
autonomous than deepening. It is often triggered by discrete decisions to invest in new capabilities through more formal mechanisms like R\&D programs or acquisitions. Note, companies can choose to broaden or deepen both their general-purpose capabilities and their market-specific capabilities.

Considering the two dimensions discussed above—broadening vs. deepening and general-purpose vs. market-specific-provides a map of the critical choices in capability search (see Figure 3 below). Different search strategies involve different degrees of supply side and demand side uncertainty. Deepening strategies entail lower supply side uncertainty than broadening strategies. Creating general-purpose capabilities involves lower demand side uncertainty than does creating market-specific capabilities.

\section{Figure 3 Mapping Capability Strategy Choices}

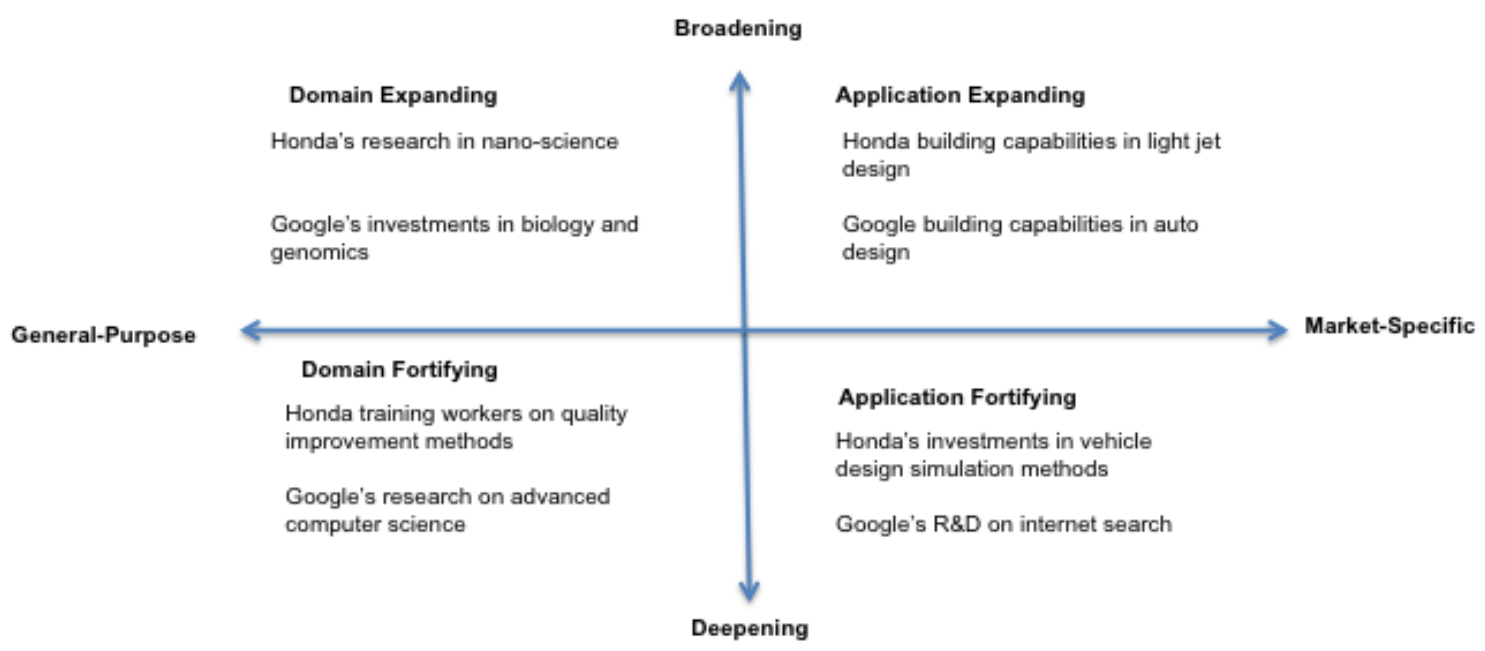

At any point in time, companies may make multiple types of capability enhancing investments (as the examples above were also designed to illustrate). It should also be clear that certain strategies might require investments in specific combinations of new capabilities. For instance, as Google pursues a strategy to enter markets like vehicles and health care, it must both broaden its general-purpose capabilities (e.g. hardware and mechanical design for cars, medical science for health care) as well as its market-specific capabilities (e.g. vehicle design, diagnosis of mental health problems, etc.). A firm's capability strategy is defined by its pattern of search and the allocation of its efforts across these different types of capabilities. 


\section{Capability Strategy and Penrosian Diversification: An Illustration}

As noted above, a robust capabilities-based theory of strategy should connect a firm's capability choices with product market strategies. To illustrate the potential of the framework presented above to make this link, we explore a fairly common strategy: diversification of an existing firm into new markets. Diversification has been a focus of strategy research (and practice) for many decades, and it has been a point of particular interest for scholars working with both resource-based and capabilities-base perspectives (see e.g. Teece 1982, Montgomery and Wernerfelt 1988, Teece et al 1994). As such, it provides an ideal venue in which to 'test' whether the framework above can identify and help resolve unexplained elements of the phenomenon.

As Edith Penrose first pointed out in 1959, a common strategy for firm growth is to expand into new lines of business by utilizing common fixed resources. The Penrosian growth theory starts with the premise that firms make investments in a set of resources (like brand, distribution, technology, etc.) to serve their initial market. When these resources entail high fixed costs and cannot be fully utilized in the initial market, profitable opportunities exist for firms to use them in new markets. A number of scholars extended her core theories to develop robust explanations of the multi-product firm (Teece 1982) and to explain why diversification into "related" lines of business tended to be more profitable than "unrelated" diversification (Montgomery and Wernerfelt 1988, Teece et al. 1994, Helfat and Eisenhardt 2004). The core theoretical elements of Penrosian growth process are economies of scale (which lead to assets being under-utilized in "core" markets), economies of scope (which enable assets to be deployed into new markets with low marginal cost) and transaction cost economics (which make it more profitable for a firm to capture rents on these assets via internal diversification than through licensing).

The Penrosian growth story is one of re-deploying assets from one sector to another. Such assets, of course, can include capabilities. There is a puzzle, however, that cannot be explained by this perspective. Diversification is almost never purely a process of exploiting or redeploying existing capabilities; it usually requires the creation of new market-specific capabilities. Consider the example of Virgin Group (for details, see Pisano and Corsi 2012), which 
has diversified into a broad range of businesses, including music, airlines, trains, radio, broadband communication, fitness centers, insurance and banking, gaming and, most recently, primary care physician practices. From a traditional Penrosian perspective, this is a simple story of Virgin leveraging its powerful brand that has come to stand for excellent (and entertaining) customer service. ${ }^{9}$ But, operationally, these businesses are very different. The capabilities to run an airline are completely different than those required to operate a bank or a fitness center. Virgin's diversification has required both redeployment of some general-purpose capabilities and the creation of some new (and very different) market-specific capabilities.

Or consider an example given earlier in this paper-Honda's entry into the light private jet market. Broadly speaking, jets and cars (and motorcycles and lawn and garden equipment) both utilize similar general-purpose capabilities in mechanical engineering and (increasingly) electronic engineering. However, to describe Honda's diversification strategy as leveraging "core competences" in mechanical engineering would be to completely ignore the high degree of specialized design capability required in each of these segments. An airplane is not a car with wings. To enter the aircraft market, Honda has head to develop a host of new market specific capabilities in such things as wing and fuselage design and fabrication, cabin pressure control systems, aerodynamic breaking, methods for fastening joints under severe loads ${ }^{10}$, avionics, and others.

Given that diversification requires access to new market-specific capabilities, two questions are pertinent. First, can these capabilities be acquired through some type of contractual or market mechanism? Strategically, it may not be necessary to create all the market-specific capabilities required for entry (Teece 1986, Pisano 1991). Honda, for instance, partnered with GE in the creation of the engine for its light jet. Virgin outsources many of the functions required to operate in its various businesses (such as aircraft maintenance). Google does not necessarily need to engineer a whole vehicle to enter the car industry if it can access car-specific capabilities through partnerships or outsourcing. Traditional transaction cost theory can help us to determine

\footnotetext{
${ }^{9}$ With the exception of primary practices in the UK, Virgin always uses the Virgin brand in its new businesses (Virgin Atlantic, Virgin Active, Virgin Casino, Virgin Mobile, Virgin Money, etc.).

${ }^{10}$ The loads an airframe must withstand are so much greater than those experienced by a car that Honda even had to develop new capabilities in bolted joint design and the measurement of sheer forces US Patent \#20070144267A1, K.

Sato, H. Murayam, K. Kageyama, Honda Motor Company Ltd., granted 6/28/2007.
} 
which capabilities can be safely outsourced and which need to be developed de novo. For complex systems, the degree of modularity in the product architecture has a powerful effect (Baldwin and Clark 2000). Because modularity facilitates outsourcing, it enables new entrants to avoid developing new market-specific capabilities.

If capabilities cannot be outsourced or acquired through some type of contractual mechanism, then the firm faces a second question: can it develop the required market-specific capabilities de novo? Posed in the language we used in Figure 1, where on the "strategic relevance" spectrum (trivial to infeasible) do these new capabilities lie? What are the capability boundaries of an enterprise? There is a general sense in the literature that companies can successfully accumulate new capabilities that are "closely related" to their existing stock of knowledge. Teece et al. (1994: page 17) hypothesize: "If firms attempt to enter new markets with new technologies, failure is likely to be the norm because the effort is likely to be outside the firm's learning range (italics added)." What the learning range is for any given firm, however, is not specified. Current theories of Penrosian entry do not help us predict which new market specific capabilities a firm might be able to develop and which may be beyond its 'learning range.'

The framework elucidated in this paper provides a starting point for getting at the question of the firm's likelihood of successful entry. The framework suggests that diversification could entail one of three basic capability strategies:

1) Create new market-specific capabilities that utilize existing general-purpose capabilities ("application expanding" search only).

2) Create new market-specific capabilities and deepen existing to general-purpose capabilities ("domain fortifying" plus "application expanding" search).

3) Create new market-specific capabilities that require the firm to broaden its generalpurpose capabilities to new domains ("domain expanding" plus "application expanding" search).

We examine each briefly below and the implications for the likelihood of successful entry.

\section{New Market-Specific Capabilities That Leverage Existing General-Purpose Capabilities}

Under this scenario, new market-specific capabilities draw upon the firm's existing general-purpose capabilities. A good example would be the virtual maps Google created to help 
its autonomous vehicles navigate. Creating these maps and integrating them into an autonomous vehicle navigation system required creating relatively "car-specific" capabilities. However, this process draws on Google's general-purpose capabilities in data (image) collection and analysis. Chris Urmson, Google's head of self-driving car programs commented, "It's one of those things that Google, as a company, has had some experience with [e.g. Google Maps product and Street View]. We go around and we've collected this data so you can have this wonderful experience of visiting places remotely. And it's a very similar capability to the one we use here."11 Another example would be the capabilities that enabled Amazon.com to enter the market for cloud based computing services (Amazon Web Services). In describing the capabilities the company required, Adam Jassey who started and currently runs Amazon Web Services commented, "To run Amazon.com, we had to build good services very deep in the software stack - things like data storage, computing, database functionality, and messaging. We learned a lot of lessons, made a lot of improvements, and were forced to do things at a significant scale and level of reliability. In many ways, we had been working on the foundation of AWS since Amazon's inception but didn't really know it."12

These are examples where strength in a particular set of general-purpose capabilities makes it easier for the firm to develop required new market-specific capabilities. The firm's existing general-purpose capabilities complement the required new market-specific capabilities. The likelihood of successly developing new market-specific capabilities should be higher if those new capabilities also utilize the firm's existing general-purpose capabilities.

\section{New Market-Specific Capabilities and Deepening of Existing General Purpose}

\section{Capabilities}

In the above scenario, the firm's existing level of competence in some general-purpose capability is adequate to enable the creation of a new market-specific capability. In the example given, Google presumably had "adequate" capabilities in data collection and analysis to create

\footnotetext{
11 "The Trick That Makes Google's Self-Driving Cars Work," The Atlantic, Alexis Madrigal, May 15, 2014 (http://www.theatlantic.com/technology/archive/2014/05/all-the-world-a-track-the-trick-that-makes-googles-self-drivingcars-work/370871/)

${ }^{12}$ Amazon Web Services, HBS case number 609-048, page 4.
} 
the necessary maps and Amazon had "adequate" capabilities in data storage, computing, messaging, and database functionality. In some cases, though, entry into a new market can require "upgrading" of the firm's existing general-purpose capabilities. This happens when the new market has requirements that exceed those of the firm's existing markets. Understanding aerodynamics is important in both car design and aircraft design, but the latter requires much more sophisticated competence than the former (aerodynamics is important in car design; it is everything in aircraft design). Honda clearly had some competence in aerodynamics due to its experience in automobiles, but it likely needed to greatly deepen those competences to enter the jet market.

Compared to the first scenario (market-specific capability expansion only), this scenario creates an extra burden on the firm. Not only must it succeed in developing new market-specific capabilities, but it must also invest in its deepening its existing general-purpose capabilities. The risks of failure are likely to be relatively low given that the firm is still working within its existing base of competences. There is a cost, of course, which affects the economics of entry. If the costs of improving general-purpose capabilities to meet the needs of a new market are high enough, then entry could become unattractive. A firm likely has a greater incentive to deepen general-purpose capabilities that are also firm-specific because these presumably offer greater appropriability of returns.

\section{Create New Market-Specific Capabilities That Require New General-Purpose}

\section{Capabilities}

Many diversification strategies require firms to broaden their base of general-purpose capabilities. If Google were to enter the car market directly, it would need to develop a host of 'car-specific' engineering and design capabilities derived from mechanical engineering. This is obviously more challenging than deepening its existing capabilities in data science, artificial intelligence, and machine learning. Likewise, traditional car companies would need to broaden their base of general-purpose capabilities to encompass the things Google knows how to do. The framework in this paper views the competition between a Penrosian entrant and an 
incumbent as one of "race" to acquire the relevant general-purpose and market-specific capabilities.

We currently have very little theory or even empirical understanding about what might make some particular body of general-purpose capability or market-specific capability harder (or easier) for some firms to acquire. Some domains might be easier to master than others due to differences in the maturity and diffusion of the knowledge base, availability of skilled personnel, and the competitive positions of rivals. Would it be less costly for Google to acquire capabilities in car design and mechanical engineering than it would be for Ford to acquire capabilities in autonomous vehicle control and machine learning, artificial intelligence, and data science? It could well be that because mechanical engineering is more mature and more diffuse, Google would have an easier time mastering those skills than Ford would have mastering Google's skills. Here again, firm-specificity of general-purpose capabilities may also matter. If Google's generalpurpose capabilities are somewhat unique and difficult to imitate, but those of incumbent auto companies are not, then it suggest that Google would have the upper hand post-entry.

The above discussion was designed to illustrate how the framework presented in this paper might aid the exploration of a fairly common strategy, namely Penrosian diversification. The problem of Penrosian diversification is framed differently than in traditional resource-based analyses. Rather than being one of leveraging common assets (capabilities) across sectors, the framework presented here suggests that the critical problem is one of creating new capabilities required to serve a new market. Whether entry succeeds or fails depends on whether the firm can create these new capabilities. It highlighted a number of different scenarios under which new capability creation might occur, each with implications for the likelihood of success. A number of testable propositions follow from the analysis:

1. Complementarities between firm-specific general-purpose capabilities and new market-specific capabilities facilitate profitable Penrosian diversification strategies.

2. Entry requiring deepening existing firm-specific general-purpose capabilities is more likely to be successful than entry requiring broadening general-purpose capabilities.

3. Entry requiring the creation of new market-specific capabilities and the creation of new general-purpose capabilities is the least likely to succeed among the three (all 
other things being equal).

4. A firm is more likely to be able to broaden its base of general-purpose capabilities if those new general-purpose capabilities lie in a more mature and highly diffused domain.

5. Penrosian diversification is likely to fail if incumbents in target markets possess difficult to imitate market-specific capabilities.

\section{CONCLUSION}

This paper attempted to address an important gap in the capabilities literature. While most scholars agree now that capabilities are important to competitive advantage, we have not had a way to articulate what a capability strategy might look like. This paper offered a concept of capability strategy built around the concepts of choice, commitment, and search. It views the firm's capability problem as one of choosing between different search strategies (broadening versus deepening) for different kinds of capabilities (general-purpose vs. market-specific). The distinction between general-purpose capabilities and market-specific capabilities helps us understand different levels of commitment (and thus risk) inherent in different capability strategies.

A number of potential implications emerge from the framework. First, it highlights the potential strategic value of general-purpose capabilities. These have generally not been a focus of strategy research. But the framework here suggests they have value in two respects: they create options for future market entry and they can be complementary to market-specific capabilities. Consistent with the empirical findings of Bloom and van Reenen (2010), the framework suggests that general-purpose management capabilities rooted in such things as control and incentive systems, hiring and promotion practices, quality management systems, and corporate governance may contribute to performance differences across firms.

Second, the framework suggests that familiar notions like "core competence" are at best incomplete in explaining competitive advantage and diversification. The concept of core competence makes no distinction between those capabilities that can be leveraged across markets and those that are specific to a particular market. These differences, as we have noted, 
have profound implications for entry strategies and competitive advantage within markets. While general-purpose capabilities are necessary for advantage, they are not sufficient. Firms always need to develop market-specific capabilities to compete.

Finally, capability search strategy involves an inter-play between two types of uncertainty: supply side uncertainty to create new capabilities and demand side uncertainty concerning the value of those capabilities. More mature markets presumably have lower demand side uncertainty, and this may explain the tendency of incumbents in mature markets to focus on deepening their repertoire of highly market-specific capabilities. Less mature markets have higher demand side uncertainty, and this would argue for search strategies emphasizing generalpurpose capabilities. This may explain why new entrants (which initially lack market-specific capabilities) are better able to enter new markets than mature ones. The firm's optimal search strategy also depends on its existing capabilities: supply side uncertainty increases when the strength of complementarities between the firm's existing capabilities and new capabilities is weaker.

The framework presented in this paper highlights some important gaps in our theoretical and empirical knowledge. These gaps should serve as targets for future research. First, a major empirical gap concerns the typical patterns of investments by firms in different capability enhancing efforts. We simply do not know, for instance, how much firms in different industries tend to devote to deepening or broadening their general-purpose and market-specific capabilities. This would be a good starting point to assess whether certain kinds of capability strategies are associated with different kinds of product market strategies and competitive situations. Similarly, we have little insight about the challenges firms face in developing new market-specific and new general-purpose capabilities. Is it easier in some contexts than others? When are market-specific capabilities relatively easy to imitate or acquire? In contrast, when are they a potent barrier to entry? This paper offered some conjectures as a way to motivate discussion, but empirical work on the topic is sorely needed. 
A second big gap in our theoretical and empirical knowledge concerns judgments about the range of capabilities any given firm can pursue over some specific time period. For both Schumpeterian entry, competition involves races between incumbents and new entrants to create new market-specific and new general-purpose capabilities. As of now, we have no real way to predict theoretically how such competitions will pan out. We do not know which broadening moves are likely to succeed and which ones will fail (beyond the obvious extremes). The paper argued that a strategic theory of capabilities needs to focus on the "middle ground" of capabilities that are neither trivial for the firm to create in the short-term nor impossible to create over the long-term. But this "middle ground" is broad, and much more empirical research needs to be done to help identify systematic factors that shape which capability expansions are economically feasible and which ones are not.

A third gap ripe for research concerns what is required for a firm to alter its capability search strategies. For instance, if a firm has focused for the past several decades on marketspecific capability deepening, how difficult is it to shift to a strategy focused more on broadening capabilities? Are there high-level organizational routines (like governance structures, resource allocation processes, etc.) that influence which capability strategies are open to the firm at any given time? We simply have no data on this subject to even speculate.

Finally, the framework here needs to be further developed and tested empirically in a wide range of competitive situations. The brief analysis of Penrosian diversification was designed to provide an illustration of the potential. Much more empirical work needs to be done on this context alone. There are also a variety of other competitive contexts that might be examined using the framework, including situations of 'disruptive' Schumpeterian entry as well as competition in relatively stable oligopolistic markets. A good theory of capability-based strategy should be able to deal with the full range of competitive contexts and link important capability strategy decisions back to relevant details of those contexts.

Addressing the above gaps will require in-depth longitudinal investigations of the evolution of specific technological and operating processes within firms and industries. We will 
need to examine the allocation of investment resources across different kinds of capabilities and the consequences of those decisions for operating performance. We will need to understand a lot more about the details of capability creating activities, and why some work and some fail. These kinds of data are typically not found in public sources, but require researchers to go into the field and inside organizations to capture primary quantitative and qualitative data. While such studies have fallen out of favor in academia in the recent past, they will be absolutely essential if we are to make significant progress on a topic of enormous importance to the practice of management. 


\section{References}

Abernathy, William J., Kim B. Clark, and Alan M. Kantrow. Industrial Renaissance: Producing a Competitive Future in America. New York: Basic Books, 1983.

Adler, Paul S., and Kim B. Clark. "Behind the Learning Curve: A Sketch of the Learning Process." Management Science 37.3 (1991): 267-281.

Andriani, Pierpaolo and Gino Cattini, "Exaptation as a Source of Creativity, Innovation, and Diversity: Introduction to the Special Section." Industrial and Corporate Change, Vol 25, no 1 (February 2016): 115-132.

Amit, R, and P. Schoemaker. "Strategic Assets and Organizational Rent." Strategic Management Journal 141 (1993): 33-46.

Andrews, Kenneth. The Concept of Corporate Strategy. Irwin: Homewood, 1971.

Baldwin, Carliss and Kim Clark. Design Rules: The Power of Modularity. Cambridge, MA: MIT Press, 2000.

Barney, Jay. "Strategic Factor Markets: Expectations, Luck, and Business Strategy." Management Science 32.10 (1986): 1231-1241.

Barney, Jay. "Firm Resources and Sustained Competitive Advantage." Journal of Management 17 (1991): 99-120.

Bloom, Nicholas and John van Reenen. "Measuring and Explaining Management Practices Across Firms and Countries." The Quarterly Journal of Economics 122.4 (2007):1351-1408.

Bloom, Nicholas and John Van Reenen. "Why Do Management Practices Differ Across Firms and Countries?" Journal of Economic Perspectives 24.1 (2010): 203-24.

Breschi, Stefano and Franco Malerba. "Sectoral Innovation Systems: Technological Regimes, Schumpeterian Dynamics, and Spatial Boundaries." in Charles Edquist (ed.), Systems of Innovation: Technology, Institutions, and Organization. Oxon, UK: Pinter (1997): 130-152.

Chandler, Alfred. Scale and Scope: The Dynamics of Industrial Capitalism. Cambridge, MA: Harvard University Press, 1990.

Christensen, Clayton. The Innovator's Dilemma: When New Technologies Cause Great Firms to Fail. Boston: Harvard Business Review Press, 1997.

Clark, Kim. "The Interaction of Design Hierarchies and Market Concepts in Technological Evolution." Research Policy. Volume 14, no. 5: 235-251. 1985

Clark, Kim and Takahiro Fujimoto. Product Development Performance: Strategy, Organization, and Management in the World Auto Industry. Boston: Harvard Business School Press, 1990.

Dierickx, Ingemar and Karel Cool. "Asset Stock Accumulation and Sustainability of Competitive Advantage." Management Science: vol 35, no 12 (1989): 1504-1511.

Dosi, Giovanni. "Technological Paradigms and Technological Trajectories: A Suggested Interpretation of the Determinants of the Direction of Technical Change. Research Policy, 11 (1982): 147-162.

Dosi, Giovanni. Technical Change and Industrial Transformation. New York: St. Martin's Press, 1984. 
Dosi, Giovanni, Marco Faillo, and Luigi Marengo. "Organizational Capabilities, Patterns of Knowledge Accumulation and Governance Structures in Business Firms: an

Introduction." Organization Studies 29.8-9 (2008): 1165-1185.

Dew, Nick, Brent Goldfarb, and Saras Sarasvathy. "Optimal Inertia: When Organizations Should Fail." Advances in Strategic Management 23 (2006): 73-99.

Edmondson, Amy C., Richard M. Bohmer, and Gary P. Pisano. "Disrupted Routines: Team Learning and New Technology Implementation in Hospitals." Administrative Science Quarterly 46.4 (2001): 685-716.

Eisenhardt, K. M. and Martin, J. A. (2000), Dynamic capabilities: what are they?. Strategic Management Journal., 21: 1105-1121.

Fujimoto, Takahiro. Evolution of a Manufacturing System at Toyota. Oxford: Oxford University Press, 1999.

Garvin, David. Managing Quality. New York: Free Press, 1988.

Ghemawat, Pankaj. Commitment: The Dynamics of Strategy. New York: Free Press, 1991.

Ghemawat, Pankaj and Gary Pisano, "Sustaining Superior Performance: Commitments and Capabilities," Harvard Business School Press, note number 9-798-008. July 1997.

Hannan, Michael T., and John Freeman. "The Population Ecology of Organizations." American Journal of Sociology (1977): 929-964.

Hayes, Robert H. "Strategic Planning-Forward in Reverse." Harvard Business Review 63.6 (1985).

Hayes, Robert and Kim Clark. "Why Some Factories Are More Productive Than Others." Harvard Business Review 64.5 (1986): 66-73.

Helfat, C. E. and Eisenhardt, K. M. "Inter-temporal economies of scope, organizational modularity, and the dynamics of diversification." Strategic Management Journal., 25 (2004): 1217-1232.

Helfat, Constance and Margaret Peteraf . "Understanding Dynamic Capabilities: Progress Along a Developmental Path." Strategic organization 7.1(2009): 91.

Helfat, Constance and Margaret Peteraf. "Managerial Cognitive Capabilities and the Microfoundations of Dynamic Capabilities." Strategic Management Journal (2014).

Henderson, Rebecca and lan Cockburn. "Measuring Competence: Exploring Firm Effects in Pharmaceutical Research." Strategic Management Journal 15.S1(1994): 63-84.

Henderson, Rebecca and Kim Clark. "The Reconfiguration of Existing Product Technology and the Failure of Established Firms." Administrative Science Quarterly (1990): 9-30.

Huckman, Robert, Gary Pisano and Liz Kind. "Amazon Web Services" Harvard Business School case number 9-609-048, Boston, MA. Harvard Business School Publishing. 2012.

lansiti, Marco. Technology Integration: Making Critical Choices in a Dynamic World. Boston, MA: Harvard Business School Press, 1998.

Klepper, Steven. "Industry Life Cycles." Industrial and Corporate Change 6.1 (1997): 145-182. 
Kuhn, Thomas. S. The Structure of Scientific Revolutions. Chicago: University of Chicago Press, 1962.

Leonard Barton, Dorothy. "Core Capabilities and Core Rigidities: a Paradox in Managing New Product Development." Strategic Management Journal 13.S1 (1992): 111-125.

Lippman, Steven and Richard Rumelt. "Uncertain Imitability: An Analysis of Inter-Firm Differences in Efficiency Under Competition." Bell Journal of Economics 13 (1982): 413-438.

Madrigal, Alexis. "The Trick that Makes Google's Self-Driving Cars Work." The Atlantic, May 15, 2014. http://www.theatlantic.com/technology/archive/2014/05/all-the-world-a-track-the-trick-thatmakes-googles-self-driving-cars-work/370871/)

Malerba, Franco. The Semiconductor Business: The Economics of Rapid Growth and Decline. University of Wisconsin Press, 1985.

March, James G. "Exploration and Exploitation in Organizational Learning." Organization Science 2.1 (1991): 71-87.

Paul Milgrom and John Roberts. "The Economics of Modern Manufacturing." American Economic Review, volume 8, no. 3 (1990): 511-528.

Montgomery, Cynthia and Birger Wernerfelt. "Diversification,Rricardian Rents, and Tobin's Q." The RAND Journal of Economics 19.4 (1988): 623-632.

Nelson, Richard and Sidney Winter. An Evolutionary Theory of Economic Change. Cambridge: Harvard University Press, 1982.

O'Reilly, Charles A. and Michael L. Tushman. "Ambidexterity As a Dynamic Capability: Resolving the Innovator's Dilemma." Research in organizational behavior 28 (2008): 185-206.

Penrose, Edith. The Theory of the Growth of the Firm. Wiley: New York, 1959.

Peteraf, Margaret, Giada Di Stefano, and Gianmario Verona. "The Elephant in the Room of Dynamic Capabilities: Bringing Two Diverging Conversations Together." Strategic Management Journal 34.12 (2013): 1389-1410.

Pisano, Gary "The Governance of Innovation, Vertical Integration and Collaborative Arrangements in the Biotechnology Industry, Research Policy 20, no. 3 (June 1991): 237-249.

Pisano, Gary. The Development Factory. Boston, MA: Harvard Business School Press, (1996).

Pisano, Gary. Science Business: The Promise, The Reality, and the Future of Biotech. Boston, MA: Harvard Business Review Press, 2006.

Pisano, Gary P., Richard M. Bohmer, and Amy C. Edmondson. "Organizational Differences in Rates of Learning: Evidence from the Adoption of Minimally Invasive Cardiac Surgery." Management Science 47.6 (2001): 752-768.

Pisano, Gary. "Teaching Note for 'Intel Corporation: 1968-1997” HBS case number 797137. Boston, MA: Harvard Business School Publishing, 2001.

Pisano, Gary and Elena Corsi “Virgin Group: Finding New Avenues for Growth." HBS Case Number 6122070. Boston, MA.: Harvard Business School Publishing, 2012.

Porter, Michael. Competitive Strategy. New York: Free Press, 1980. 
Porter, Michael. "Towards a Dynamic Theory of Strategy." Strategic Management Journal (1991): volume 12: 95-117.

Porter, Michael. "What is Strategy?" Harvard Business Review, November-December, 1996.

Prahalad, C. K. and Gary Hamel. "The Core Competence of the Corporation." Harvard Business Review (1990): 235-256.

Rivkin, Jan and Nicolaj Siggelkow. "Balancing Search and Stability: Interdependencies Among Elements of Organizational Design.” Management Science. 49: 3 (2003): 290-311

Rumelt, Richard. "Towards a Strategic Theory of the Firm," in Lamb, Robert B. (ed.) Competitive Strategic Management, Englewood Cliffs, NJ. Prentice Hall, 557-570, 1984.

Rumelt, Richard. "How Much Does Industry Matter? Strategic Management Journal 12.3 (1991): 167-185.

Teece, David. "Toward an Economic Theory of the Multiproduct Firm." Journal of Economic Behavior and Organization 3.1 (1982): 39-63.

Teece, David. "Profiting From Technology Innovation: Implications for Integration, Collaboration, Licensing, and Public Policy." Research Policy. Vol 15. No. 6 (1986):285-305.

Teece, David J., Giovanni Dosi, Richard Rumelt, and Sidney Winter. "Understanding Corporate Coherence: Theory and Evidence." Journal of Economic Behavior \& Organization 23.1(1994): 130.

Teece, David and Gary P. Pisano. "The Dynamic Capabilities of Firms: An Introduction." Industrial and Corporate Change 3.3 (1994): 537-556.

Teece, David J., Gary P. Pisano, and Amy Shuen. "Dynamic Capabilities and Strategic Management." Strategic Management Journal (1997): 509-33.

Tripsas, Mary. "Unraveling the Process of Creative Destruction: Complementary Assets and Incumbent Survival in the Typesetter Industry." Strategic Management Journal 18.1 (1997): 119142.

Tripsas, Mary, and Giovanni Gavetti. "Capabilities, Cognition, and Inertia: Evidence from Digital Imaging." Strategic Management Journal 21.10-11 (2000): 1147-1161. .

Tushman, Michael and Phillip Anderson. "Technological Discontinuities and Organizational Environments.” Administrative Science Quarterly (1986): 439-456.

Upton, David. "What Really Makes Factories Flexible?" Harvard Business Review 73.4 (1995): 74-84.

Wernerfelt, Birger. "A Resource-Based View of the Firm." Strategic Management Journal 5.2 (1984): 171-180.

Winter, Sidney. "Knowledge and Competence as Strategic Assets." The Strategic Management of Intellectual Capital (1987): 165-187.

Winter, Sidney. "Understanding Dynamic Capabilities." Strategic Management Journal 24.10 (2003): 991-995. .

Womack, J., D. Jones, and D. Roos. The Machine That Changed the World. New York: Simon \& Shuster, 1991. 